\title{
A green desuperheater for an energetic efficient alternative to the decompression valve in biomass supercritical water hydrolysis process. CFD simulation.
}

Luis Vaquerizo, María José Cocero*

High Pressure Processes Group, Department of Chemical Engineering and Environmental Technology, University of Valladolid (Spain). Prado de la Magdalena s/n. 47011, Valladolid, Spain.

* Corresponding author. Tel: +34 983423174; fax: +34 983423013.

E-mail addresses: lvaquerizo@iq.uva.es (L. Vaquerizo), mjcocero@iq.uva.es (M.J. Cocero)

\begin{abstract}
The supercritical water hydrolysis $(\mathrm{SCWH})$ of biomass $\left(\mathrm{P}=250 \mathrm{bara} \& \mathrm{~T}=400^{\circ} \mathrm{C}\right)$ allows directly obtaining sugars, which are high value products in the chemical industry, in reaction times lower than $0.2 \mathrm{~s}$. The process is characterized by the high selectivity values which can be obtained controlling the reaction time. Reaction kinetics show that glucose degradation is only retarded at temperatures below $250^{\circ} \mathrm{C}$. Therefore, in the traditional SCWH process, degradation control is achieved expanding the hydrolysis stream in a valve which instantaneously cools down the products. Although the selectivity values obtained are greater than $96 \%$, the pressure is wasted on the valve expansion decreasing the global energetic efficiency of the process. In this paper a CFD simulation of a desuperheater which mixes the hydrolysis product with pressurized cooling water is presented. The temperature of the hydrolysis stream decreases below $250^{\circ} \mathrm{C}$ in cooling times lower than $20 \mathrm{~ms}$ maintaining the selectivity value over $93 \%$. Furthermore, the pressure remains at 250bara increasing the global energetic efficiency of the process.
\end{abstract}

Keywords: Biomass, Hydrothermal Medium, CFD Model, Water Turbine.

\section{Highlights:}

- The hydrolysis product is cooled down in less than $20 \mathrm{~ms}$.

- The reduced cooling times allows obtaining a selectivity value of $93 \%$.

- The hydrolysis pressure, 250bara, is maintained after controlling the reaction.

- Energetic efficiency increased due to heat and pressure integration possibilities. 


\section{Introduction}

Green chemical engineering technologies are based in the substitution of large scale centralized processes by small scale decentralized processes able to use the local available raw materials (Arai et al., 2009). The supercritical water hydrolysis (SCWH) of biomass is a process which allows obtaining glucose, a building block in the chemical industry, directly from biomass (Cantero et al., 2013b). Supercritical water (SCW) (P>221bara, $\mathrm{T}>374^{\circ} \mathrm{C}$ ), which is the reaction medium, is an easily tunable fluid. Its characteristic properties can be modified just varying the pressure and temperature (Cantero et al., 2015b). Any modification in the density or the ionic product of water determines the reaction pathways and consequently, the hydrolysis products (Cantero et al., 2015a). The main advantage of this environmental friendly process is the high selectivity values obtained in the hydrolysis due to the precise control of the residence time (Adschiri, 2014; Brunner, 2014, 2009). The accurate selection of the hydrolysis time is possible due to the instantaneous heating of the raw materials and cooling of the product stream (Piqueras et al., 2017). While in the inlet of the reactor, a suspension of biomass is mixed with supercritical water reaching instantaneously the reaction temperature, in the outlet of the reactor, the product stream is decompressed in a valve being instantaneously cooled, stopping the reaction and consequently avoiding the generation( of byproducts (Cantero et al., 2013a). Therefore, the hydrolysis time is simply the residence time of the fluid inside the reactor. The implementation of different reactors or the variation of process streams flows allows easily modifying the residence time of the process.

Since the decompression of a fluid in a valve is an isoenthalpic process, the outlet stream of the valve has the same enthalpy of the inlet stream. However, as a consequence of the Joule-Thomson effect the temperature of the outlet stream is lower than the temperature of the inlet steam (when the inlet temperature is lower than the Joule-Thomson inversion temperature). In the process of supercritical water hydrolysis of biomass, the product stream is expanded from the reaction conditions $\left(\mathrm{T}=400^{\circ} \mathrm{C}\right.$ and $\mathrm{P}=250$ bara) to a pressure lower than $\mathrm{P}=40$ bara which results in a temperature lower than $\mathrm{T}=250^{\circ} \mathrm{C}$, temperature at which the reaction is intensively retarded (Cantero et al., 2015). Analyzing the downstream process, this sudden decompression in the valve results in high selectivity values (reaching maximums of 98\%) which avoids the necessity of further separation stages (Prado et al., 2016). However, from an energetic 
point of view, a decompression is not efficient since it reduces the temperature and pressure levels avoiding further possibilities of heat and pressure integration. A possible improvement of the process is the integration of biomass hydrolysis reactors with commercial gas turbines (Cantero et al., 2015). In this alternative of the SCWH process, the liquid and vapor phases generated in the expansion valve are separated in a flash. While the vapor stream of the flash is injected in the combustor of the gas turbine increasing the efficiency of the expansion, the flue gases of the gas turbine are heat integrated with the raw materials and the electricity generated in the turbine drives the high pressure pumps. Although the global efficiency of the process is increased, this process implies the consumption of natural gas in the gas turbine.

In the chemical industry, superheated steam is commonly used in the generation of mechanical power as in the case of steam turbines where the presence of liquid droplets can damage the blades of the rotor. However, in heating processes it is more favorable the use of saturated steam which is able to transfer not only sensible but latent heat. For this reason, in order to integrate the use of the two different types of steam in a sole steam network, steam desuperheaters are implemented. The concept of operation of steam desuperheaters is simple; a superheated steam stream is mixed inside the desuperheater with a liquid cooling water stream (Rahimi et al., 2016). The cooling water stream vaporizes absorbing the sensible heat transferred by the superheated steam which becomes saturated. It has to be considered that both the pressure of the superheated stream and the pressure of the cooling water shall be equal. The design of these devices is focused in the calculation of the amount of cooling water required to saturate the superheated steam and in the achievement of an efficient mixing process. In literature it is possible to find CFD simulations which model the fluid distribution and mixing effectiveness inside steam desuperheaters. The vapor and liquid phases are simulated using the discrete phase model based in the Eulerian-Lagrangian model (Rahimi et al., 2016), (Kouhikamali et al., 2012). The use of steam desuperheaters in innovative applications has been already tested. An example is the $\mathrm{CO}_{2}$ capture process where steam desuperheaters are used as temperature controllers (Zhang et al., 2014, 2013).

In this paper a supercritical water desuperheater is presented. The objective is the substitution of the decompression valve of the SCWH process by a desuperheater 
increasing the heat and pressure integration possibilities. The product stream of the hydrolysis reactor is mixed with a pressurized cooling water stream reducing its temperature to a value below $250^{\circ} \mathrm{C}$ at which it is considered that the hydrolysis reaction is retarded (Cantero et al., 2015). The cooling process is carried out in a reduced residence time avoiding selectivity losses and therefore the generation of byproducts. Later, the analysis of the temperature influence in the kinetics of the glucose degradation reaction and the study of the possible downstream process alternatives is presented.

\section{Model description}

The desuperheater presented in this paper is based in the mixture of a hydrolysis product stream composed by $81.2 \mathrm{~kg} / \mathrm{h}$ of water and $2.8 \mathrm{~kg} / \mathrm{h}$ of hydrolysis products at $400^{\circ} \mathrm{C}$ and $250 \mathrm{bara}$ and $141.8 \mathrm{~kg} / \mathrm{h}$ of a pressurized cooling water stream at $\mathrm{T}=27^{\circ} \mathrm{C}$ and $\mathrm{P}=250 \mathrm{bara}$. It is noted that the relationship between the cooling water stream and the hydrolysis stream is equal to 1.59 . Therefore, a remarkable dilution effect is produced since the mass concentration of hydrolysis products varies from $3.3 \%$ to $1.2 \%$.

In the SCWH process, the product concentration in the hydrolysis stream is a function of the biomass concentration in the feed stream. In order to operate in the optimum hydrolysis point, it is necessary to control the temperature, the pressure and the residence time of the process independently of the biomass concentration. Therefore, for an installed hydrolysis reactor and in order to avoid changes in the residence time, any modification of the final product concentration shall be achieved through variations of the biomass concentration in the suspension feed stream instead of through water flow variations. A study of the evolution of the final product concentration is presented: 


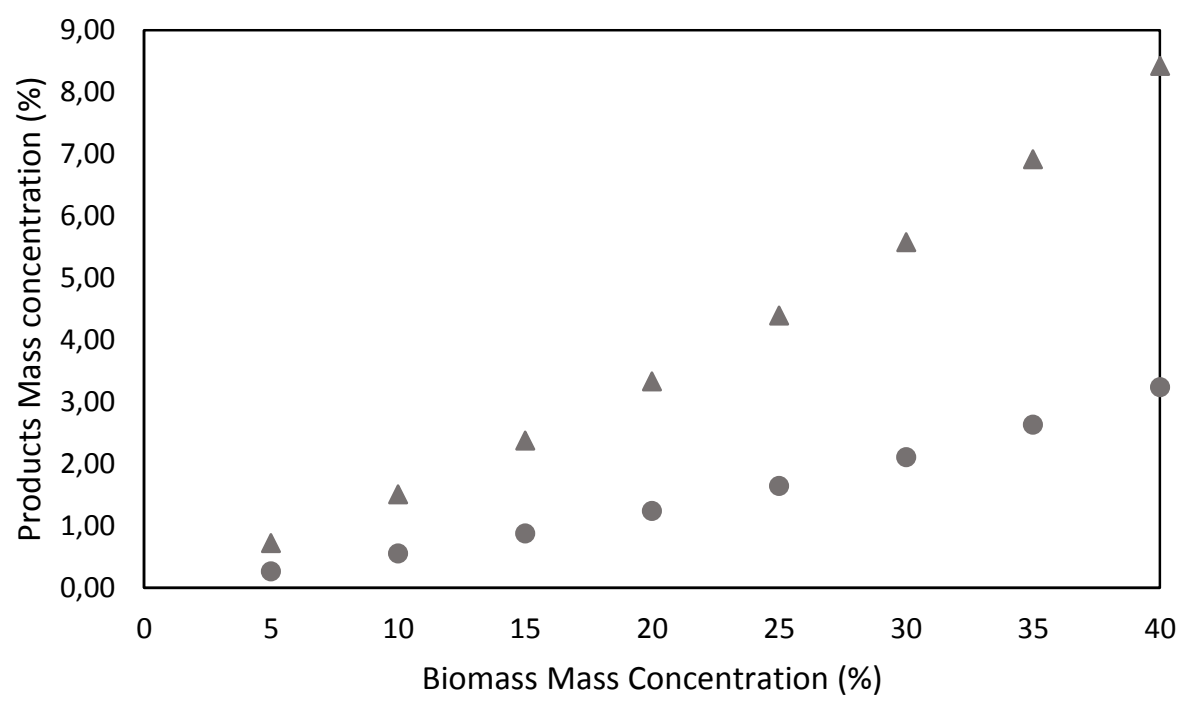

Fig 1. Evolution of the products mass concentration varying the biomass concentration in the biomass suspension feed stream. Downstream process possible concentration is not considered.

Products mass concentration after: $(\boldsymbol{\Delta})$ hydrolysis reactor, $(\bullet)$ desuperheater.

As it can be seen from Fig 1, the products concentration in the hydrolysis stream is a function of the biomass concentration in the suspension feed stream. Any increase of the biomass concentration in the suspension feed stream produces an increase in the products concentration in the hydrolysis stream. Furthermore, considering that in order to operate in the optimum residence time value the water flows of both, the biomass suspension feed stream and the supercritical water feed stream are not varied, the cooling water flow injected in the desuperheater remains constant independently of the biomass concentration in the suspension feed stream. Therefore, the products concentration in the desuperheater outlet stream is also a function of the biomass concentration in the feed stream since it also increases when the biomass concentration in the suspension feed stream is increased. For example, in this paper it has been considered that the biomass mass concentration in the suspension feed stream is $20 \%$. The products mass concentration obtained in the hydrolysis reactor outlet stream is $3.3 \%$ and in the desuperheater outlet stream is $1.2 \%$. Doubling the biomass concentration in the feed stream $(40 \%)$ would increase the products mass concentration in the hydrolysis reactor outlet stream from $3.3 \%$ to $8.4 \%$ and in the desuperheater outlet stream from $1.24 \%$ to $3.24 \%$. 
In this simulation, considering that the mass percentage of hydrolysis products inside the desuperheater is $1.24 \%$ and in order to decrease the complexity, only the water fraction of the stream has been considered. For this reason, the influence of the hydrolysis products in the variation of the physical properties has been neglected. The simulation results when a hydrolysis stream of a different concentration is considered would be identical taking into account that the water flows are not varied and that only the water fraction is considered.

The CFD simulation of the steam desuperheater was carried out solving the momentum, energy, mass and turbulence equations in the commercial software Ansys Fluent ${ }^{\circledR}$ 17.0.

\subsection{CAD model and meshing}

A 3D model of the desuperheater was created using AutoCAD® 2012. Although it is more computational intensive than a 2D model, due to the complexity of the object it was decided to carry out a 3D simulation. However, as the amount of heat exchanged between the fluid and the environment is negligible, the solid part of the desuperheater was not included in the CFD simulation.

A 400000 elements 3D mesh of the CAD model was generated using the Ansys Fluent ${ }^{\circledR}$ meshing interface. This number of cells assures the independence between the model and the mesh size.

\subsection{Physical properties}

In the simulation of a steam desuperheater, the modeling of the physical properties is especially relevant due to the strong variations of the properties between the liquid and vapor phases as for example the density, which decreases from $1000 \mathrm{~kg} / \mathrm{m}^{3}$ in liquid phase to $0.6 \mathrm{~kg} / \mathrm{m}^{3}$ in vapor phase. Although in this desuperheater the inlet streams are in liquid and supercritical state instead of in liquid and vapor state, it has to be considered that these variations could be even more pronounced as a consequence of the proximity of the critical point. An imprecise modeling of the physical properties directly affects the accuracy of the CFD simulation. The simulation of the temperature distribution and the calculation of the required cooling water flow are directly functions of the physical properties values in each point of the desuperheater. An underestimation of the required cooling water flow results in an elevated outlet temperatures at which the hydrolysis reaction is not stopped and consequently byproducts are generated. The modeling of either the density or the specific heat is particularly complex since their values vary 
from $166 \mathrm{~kg} / \mathrm{m}^{3}$ to $1000 \mathrm{~kg} / \mathrm{m}^{3}$ in the case of the density and from $76300 \mathrm{~J} / \mathrm{kg} \cdot \mathrm{K}$ to $4115 \mathrm{~J} / \mathrm{kg} \cdot \mathrm{K}$ in the case of the specific heat. For this reason, in order to improve the precision of the CFD simulation, Ansys Fluent ${ }^{\circledR}$ was directly connected with Aspen Plus ${ }^{\circledR}$ which calculates the values of the physical properties (Vaquerizo and Cocero, n.d.). The IAPWS thermodynamic model was selected in Aspen Plus®.

\subsection{Turbulence model}

The selection of an accurate turbulence model is the base to predict the distribution of the flow inside the desuperheater and consequently the temperature profile and the residence time of the fluid. In this simulation, the realizable $\mathrm{k}-\varepsilon$ turbulence model, which is considered the most precise of the $\mathrm{k}-\varepsilon$ models, was selected due to its robustness, accuracy and the lower computational effort required compared with other turbulence models (ANSYS, 2013). The behavior of the fluid in the proximities of the walls was simulated selecting the standard wall functions model.

\subsection{Boundary conditions and numerical resolution}

While the mass flow and temperature of both the cooling water inlet and the hydrolysis product inlet were specified, the outflow condition was selected in the outlet of the desuperheater. The transport and thermodynamic equations were solved selecting the couple scheme. Regarding to convergence, first order schemes were applied until convergence was reached and then they were upgraded to second order schemes. It was considered that convergence was reached when the value of the scaled residuals were lower than $10^{-3}$. 


\section{Results and discussions}

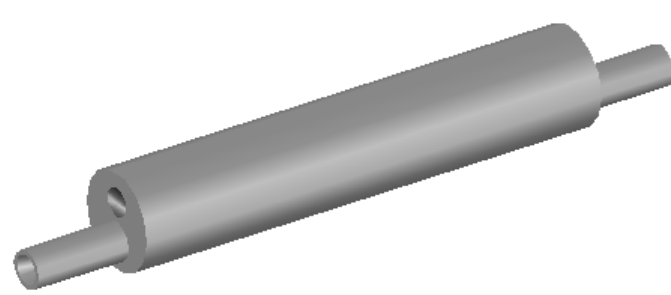

a)

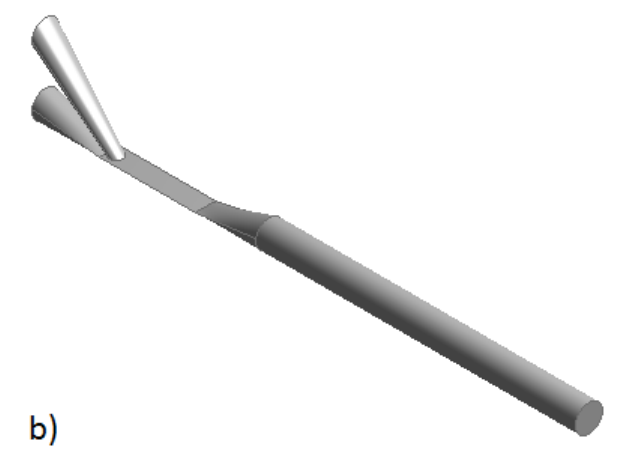

b)

Fig. 2. CAD representations of the desuperheater modeled in CFD. a) External contour. b) Internal contour.

The external and internal CAD models of the desuperheater which has been modeled in CFD are presented in Fig. 2. As it can be seen from both figures, the design of the piece is not complex since simplicity is a required piece characteristic which facilitates further manufacturing and testing possibilities. While the total length of the desuperheater is equal to $170 \mathrm{~mm}$, the inlets and outlet diameters are equal to $1 / 2$ " (tubing). In the left side, two inlets, one of pressurized cooling water (the upper one) and the other one of hydrolysis product stream are introduced in the desuperheater. Both streams are mixed in the narrowest part of the desuperheater. The objective of this mixing section is to increase the velocity and favor the mixing effects in order to be able to reduce the temperature of the hydrolysis stream as fast as possible. An almost instantaneous decrease in the temperature stops the hydrolysis reaction and avoids the generation of byproducts. In the last section, the diameter of the mixing section is increased in order to stabilize the mixture and obtain a uniform outlet stream.

Fig 3 shows the pressure and temperature evolution profiles obtained in the CFD simulation. As it can be seen, the pressure decreases from 250 bara which is the pressure in both inlets until 248 bara which is the pressure in the mixing point where the velocity reaches its maximum value. Finally in the stabilizing section, it increases up to 249 bara since the velocity is reduced when the section increases. As it can be seen from the graph, the desuperheater pressure drop is lower than 1 bar. Regarding to temperature, its evolution is directly associated to the fluid distribution along the desuperheater. In the mixing section, a difference between the central and the lateral 
section can be observed. While in the lateral section the temperature is approximately the same of the hydrolysis product stream $\left(\mathrm{T}=400^{\circ} \mathrm{C}\right)$, in the central section the temperature varies from the cooling water stream temperature $\left(\mathrm{T}=27^{\circ} \mathrm{C}\right)$ to $\mathrm{T}=236^{\circ} \mathrm{C}$ which is the temperature reached when the mixture is homogeneous. This fact proves that as the cooling water stream is injected in the central section, the points near the walls are not effectively mixed and maintain their inlet temperature. Later in the stabilizing section, the change of section produces a mixing effect and the temperature of the whole stream is equalized. From the beginning to the ending of the stabilizing section there is no appreciable variation in the temperature distribution. Moreover the average temperature is $\mathrm{T}=236^{\circ} \mathrm{C}$ with maximum values of $\mathrm{T}=250^{\circ} \mathrm{C}$ and minimum values of $\mathrm{T}=232^{\circ} \mathrm{C}$. As the maximum temperature is equal to $250^{\circ} \mathrm{C}$, it is considered that the hydrolysis reaction is retarded.

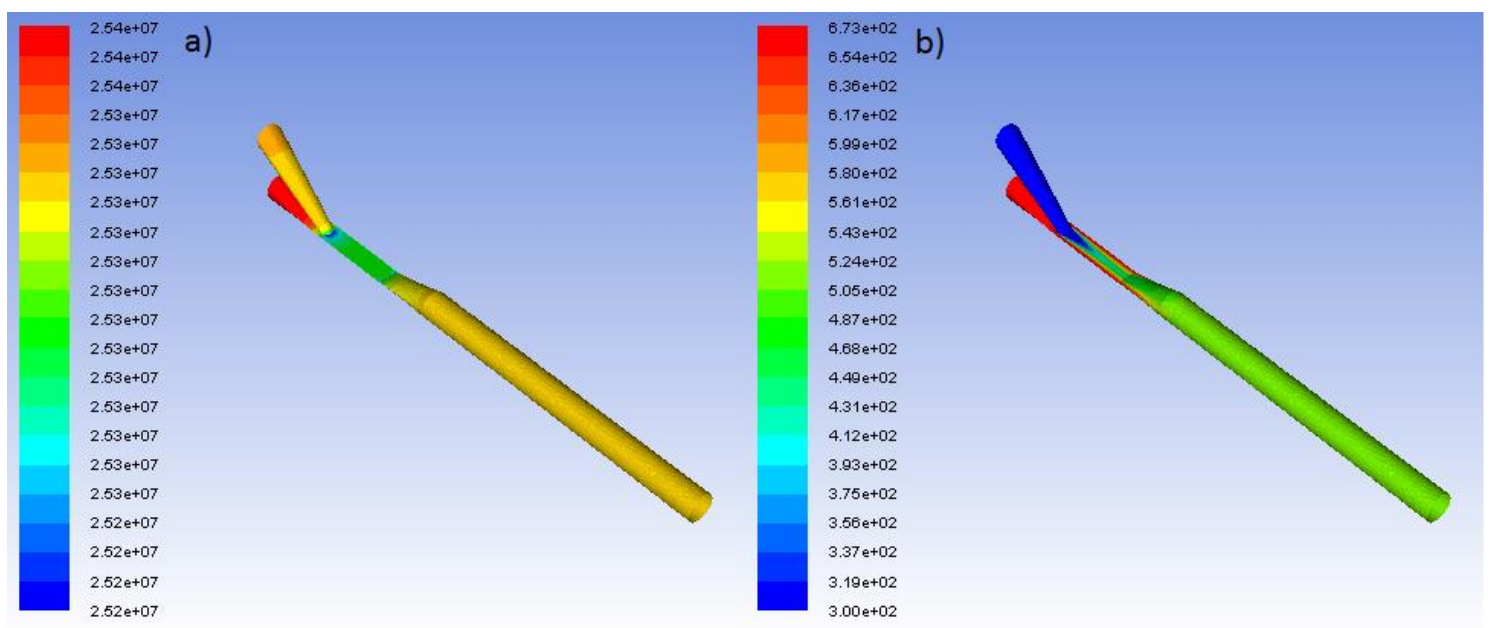

Fig 3. Mixture of the hydrolysis product stream and pressurized cooling water in the desuperheater. a) Pressure evolution profile (Pa). b) Temperature evolution profile (K).

The calculation of the temperature evolution profile is directly influenced by the values of the physical properties along the desuperheater. As it was previously said, due to the proximity of the critical point and the corresponding complexity of calculating the physical properties in this region, the CFD simulation was directly connected with Aspen Plus ${ }^{\circledR}$ which calculates the physical properties when required. Fig 4 shows the evolution of the density, specific heat, thermal conductivity and viscosity. As it can be seen, the density varies from $157 \mathrm{~kg} / \mathrm{m}^{3}$, value which corresponds with water in supercritical state, to $1000 \mathrm{~kg} / \mathrm{m}^{3}$, value which corresponds with cold pressurized water. In the mixing section, the variation of the temperature between the maximum and 
minimum values is observed. Regarding to the specific heat, an inaccurate representation of this physical property results in an imprecise temperature evolution profile as a consequence of incorrect enthalpy calculations. For this reason, it is crucial to be able to represent the variations of this magnitude in the vicinities of the critical point where it reaches maximum values. In this simulation, the outlet temperature has been validated simulating the mixture of the inlet streams in the software Aspen Plus ${ }^{\circledR}$ v.8.8. The temperature obtained in the simulation is equal to $\mathrm{T}=236^{\circ} \mathrm{C}$ which is exactly the mass average temperature obtained in the outlet region of the CFD simulation. As it can be seen from Fig 4, the specific heat values vary from $4120 \mathrm{~J} / \mathrm{kg} \cdot \mathrm{K}$ to $76000 \mathrm{~J} / \mathrm{kg} \cdot \mathrm{K}$ in the critical point. A detail of the specific heat profile in the mixing section where maximum values are reached and of the enthalpy profile in the whole desuperheater can be observed in Fig 5. Finally, the thermal conductivity and viscosity profiles are presented in Fig 4. The evolution of these physical properties is similar to the evolution profile of the density. In both cases, the thermal conductivity and the viscosity reach maximum values in the cooling water stream and minimum values in the hydrolysis stream as a consequence of the differences between the temperatures of both streams. In the mixing section the values of the physical properties vary according to the temperature profile and finally they are equalized in the final section. 


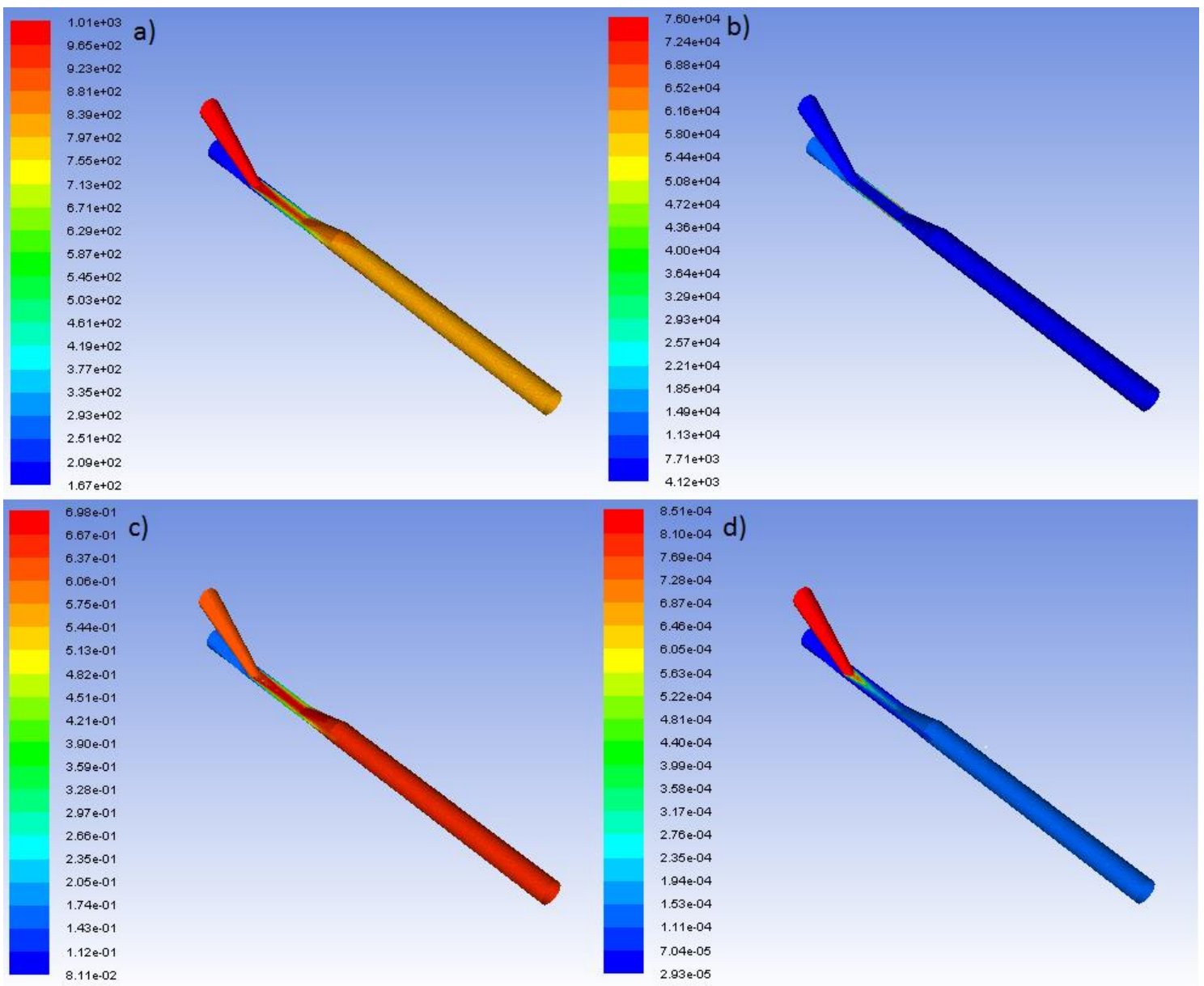

Fig 4. Mixture of the hydrolysis product stream and pressurized cooling water in the desuperheater. a) Density evolution profile $\left(\mathrm{kg} / \mathrm{m}^{3}\right)$. b) Specific heat evolution profile $(\mathrm{J} / \mathrm{kg} \cdot \mathrm{K})$.

c) Thermal conductivity evolution profile $(\mathrm{W} / \mathrm{m} \cdot \mathrm{K})$. d) Viscosity evolution profile $(\mathrm{kg} / \mathrm{m} \cdot \mathrm{s})$.

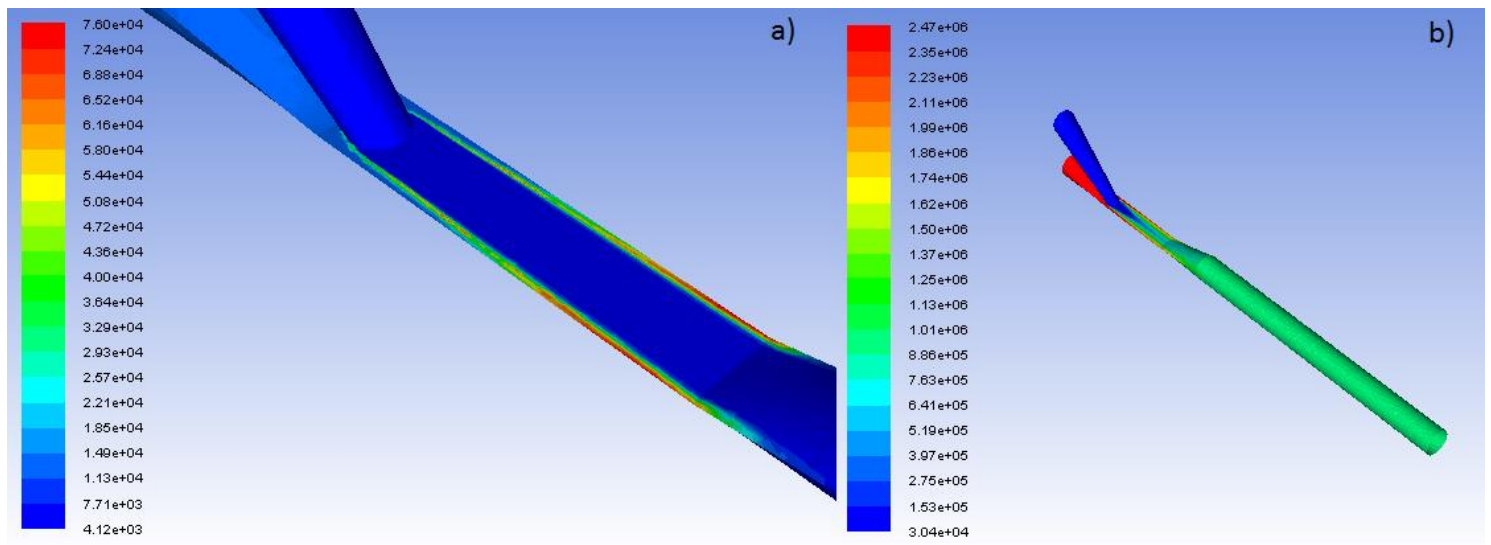

Fig 5. Mixture of the hydrolysis product stream and pressurized cooling water in the desuperheater. a) Detail of the specific heat evolution profile in the mixing section $(\mathrm{J} / \mathrm{kg} \cdot \mathrm{K})$. b) Enthalpy evolution profile $(\mathrm{J} / \mathrm{kg})$. 
Finally, in order to validate the substitution of the expansion valve in the process of supercritical water hydrolysis of biomass by a desuperheater, it is necessary to analyze what is the required time to reduce the temperature of the hydrolysis product from $400^{\circ} \mathrm{C}$, which is the hydrolysis temperature, to a value below $250^{\circ} \mathrm{C}$ at which the hydrolysis is considered to be retarded. As it can be seen from Fig 3, the temperature is stabilized at the beginning of the final section. Therefore, the cooling time is equal to the residence time from the mixing point of both inlet streams to the beginning of the final section. Fig 6 shows the evolution of the residence time along the desuperheater. As it can be seen from this figure, the cooling time is lower than $18 \mathrm{~ms}$.

The study of the influence of the cooling time shall be based in the analysis of the evolution of the selectivity with the hydrolysis time. In the studies of Cantero et al (Cantero et al., 2013b), it is demonstrated that the maximum selectivity value (98\%) in the hydrolysis of cellulose to produce soluble sugars is obtained at hydrolysis times of $15 \mathrm{~ms}$. If the hydrolysis proceeds, the selectivity value decreases proportionally to the hydrolysis time. Based in these results, if it is considered that the total hydrolysis time is equal to $33 \mathrm{~ms}$, which is equal to the hydrolysis time to achieve a maximum selectivity value $(15 \mathrm{~ms})$ plus the cooling time $(18 \mathrm{~ms})$, the value of selectivity obtained is approximately equal to $93 \%$, which is a very acceptable result. Moreover, as it can be seen in Fig 3, it has to be considered that only the molecules which flow in the proximities of the wall in the mixing section are not cooled down and therefore, in the rest of the desuperheater, the hydrolysis reaction is effectively retarded. Furthermore, when the raw material which is hydrolyzed is biomass instead of cellulose, the hydrolysis time increases one order of magnitude (Cantero et al., 2015) due to the higher complexity of the molecular structure. Therefore, the effect of the cooling time would be even more reduced.

As it has been demonstrated, the substitution of the expansion valve by a desuperheater in the process of supercritical water hydrolysis of biomass is a viable alternative. The minimum selectivity value is equal to $93 \%$. Moreover the outlet stream maintains the pressure level as the pressure drop is only of 1 bar. Furthermore, the heat content of the product stream is transferred to the cooling water stream obtaining a homogeneous outlet temperature of $236^{\circ} \mathrm{C}$. These conditions $\left(\mathrm{P}=249 \mathrm{bara}\right.$ and $\left.\mathrm{T}=236^{\circ} \mathrm{C}\right)$ allows expanding the heat and pressure integrating possibilities and consequently increase the global efficiency of the process. 


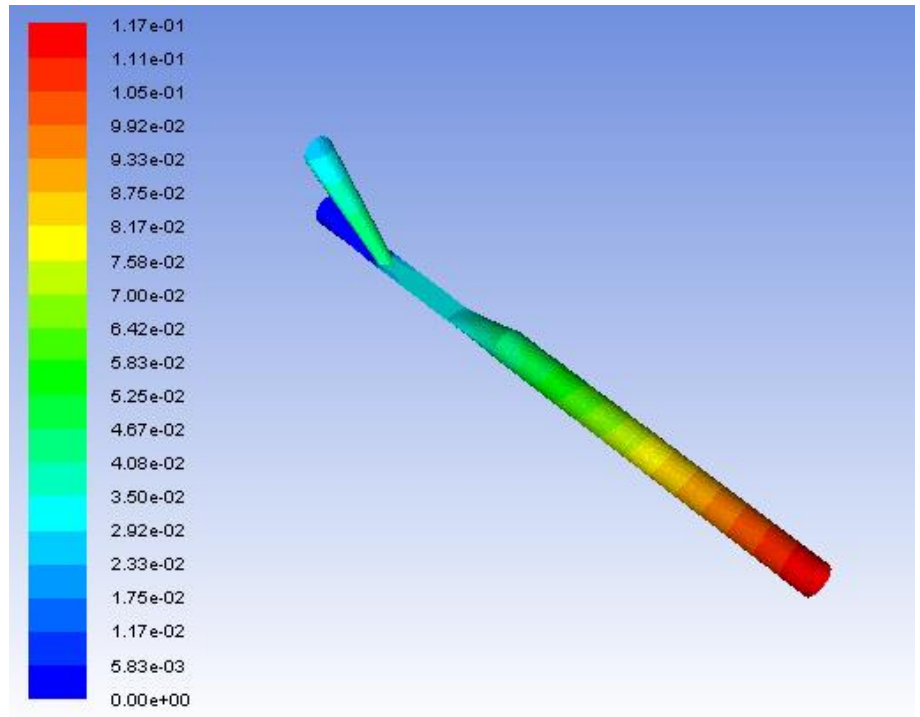

Fig 6. Mixture of the hydrolysis product stream and pressurized cooling water in the desuperheater. Cooling time evolution profile (ms).

\section{Glucose degradation analysis}

In both the desuperheater and the downstream process, the temperature control is critical. An elevated temperature produces the degradation of the glucose obtained in the hydrolysis reaction decreasing the selectivity of the process. On the other hand the final product concentration is inversely proportional to the temperature decrease in the desuperheater since as lower the temperature decrease is, higher the concentration would be. Therefore, it is necessary to analyze the glucose degradation profiles at different temperatures. The kinetics of glucose conversion which were studied by Cantero et al and Sasaki et al (Cantero et al., 2015; Sasaki et al., 2000) are followed in this paper and presented hereafter:

$$
d x_{g} /_{d t}=k_{g}\left(1-x_{g}\right)
$$

where " $\mathrm{x}_{\mathrm{g}}$ " is the glucose conversion, "t" represents the time variable (s) and " $\mathrm{k}_{\mathrm{g}}$ " is the kinetic constant $\left(\mathrm{s}^{-1}\right)$ which follows an Arrhenius type relationship:

$$
k=k_{0} \exp \left(-E a /_{R T}\right)
$$


where " $\mathrm{k}_{0}$ " is the pre-exponential factor $\left(\mathrm{Lnk}_{0}=23.1\right)$, " $\mathrm{E}_{\mathrm{a}}$ " is the activation energy $\left(E_{a}=123.3 \mathrm{~kJ} / \mathrm{mol}\right)$, " $\mathrm{R}$ " is the ideal gas constant $(\mathrm{kJ} / \mathrm{mol} / \mathrm{K})$ and " $\mathrm{T}$ " is the temperature (K). With this information and applying the fourth order Runge-Kutta method, the glucose degradation evolution profiles at different temperatures have been generated and are presented in Fig 7.

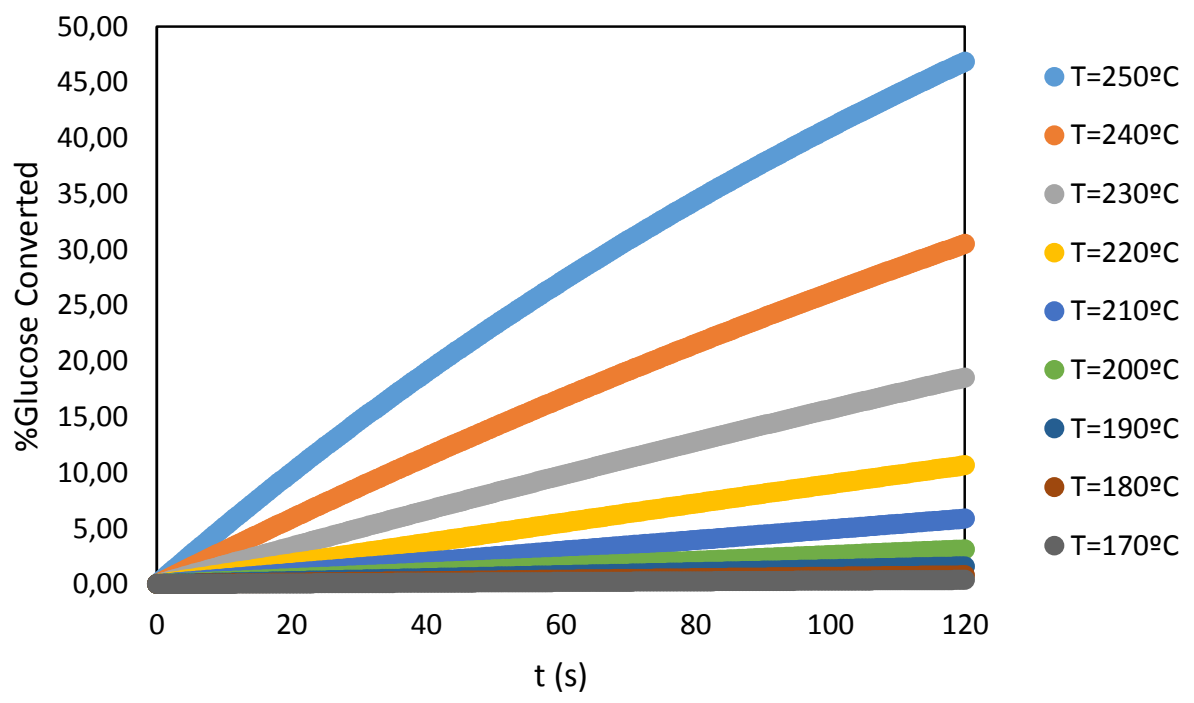

Fig 7. Glucose degradation evolution profiles at different temperatures.

As it can be seen from Fig 7, the rate of glucose degradation is directly proportional to the temperature. In the design of the desuperheater, following Cantero el al (Cantero et al., 2015) it has been considered that glucose degradation is retarded at temperatures below $250^{\circ} \mathrm{C}$. Consequently, in order to avoid temperature peaks above $250^{\circ} \mathrm{C}$, an average fluid temperature of $236^{\circ} \mathrm{C}$ has been selected. Nevertheless the simulation shows that in 20 seconds, at $236^{\circ} \mathrm{C}$ approximately the $5 \%$ of the glucose generated in the hydrolysis reaction has been already degraded. Therefore it is necessary to cool down the outlet stream of the desuperheater in order to avoid selectivity losses.

Moreover, at temperatures below $200^{\circ} \mathrm{C}$ the glucose degradation rate is reduced and therefore the desuperheater outlet stream can be introduced in pressure recovery devices avoiding selectivity losses.

As a conclusion, the simulation shows that it is necessary to cool down the desuperheater outlet stream below $200^{\circ} \mathrm{C}$ in order to avoid the degradation of the glucose generated in the hydrolysis. Three possible options to cool down the stream are 
discussed. The first option is the expansion of the stream in a valve. Although the expansion drastically decreases the temperature as a consequence of the JouleThompson effect, the pressure is wasted. Furthermore, considering the dilution of the hydrolysis product in the desuperheater, this alternative is less efficient than the traditional supercritical water hydrolysis process (expansion of the reactor outlet stream in a valve without implementing a desuperheater). The second option is the increase of the cooling water flowrate in the desuperheater in order to decrease the outlet temperature below $200^{\circ} \mathrm{C}$. Although the increase of the cooling water flowrate decreases faster the temperature of the hydrolysis product stream and consequently increases the selectivity, the dilution of the product stream is increased varying the products mass concentration from $1.2 \%$ for an outlet temperature of $236^{\circ} \mathrm{C}$ to $1.04 \%$ for an outlet stream of $200^{\circ} \mathrm{C}$. The last option is the introduction of the desuperheater outlet stream in a heat exchanger which reduces the temperature to a value below $200^{\circ} \mathrm{C}$. This option avoid increasing the dilution effect in the desuperheater since the cooling water flowrate is not increased. On the other hand, during the cooling period some glucose degradation is produced. Integrating the outlet stream of the desuperheater with the water stream which is mixed with the biomass stream in the hydrolysis reactor, it is possible to simultaneously decrease the temperature of the desuperheater stream and increase the temperature of the water stream. This option, which is the most energetic efficient, has been studied and it is presented hereafter.

The analysis of the process is based in both the calculation of the residence time of the desuperheater outlet stream in the heat exchanger and the generation of the glucose degradation evolution profile. Following the data presented in this paper, the desuperheater outlet stream, which can be represented as $223 \mathrm{~kg} / \mathrm{h}$ of water at $236^{\circ} \mathrm{C}$ and $250 \mathrm{bara}$, is mixed with $70 \mathrm{~kg} / \mathrm{h}$ of process water at $27^{\circ} \mathrm{C}$ and $250 \mathrm{bara}$. Considering that the flows are not high enough to implement a shell and tubes heat exchanger, a concentric tubes heat exchanger has been selected. The calculation of the partial heat transfer coefficient for both fluids has been performed following the Dittus-Boelter correlation for forced convection in turbulent pipe flow (Sinnot, 2005). The desuperheater outlet streams which flows along the inner tube is cooled down from $236^{\circ} \mathrm{C}$ to $190^{\circ} \mathrm{C}$ while the process water stream which flows along the concentric section created between the inner tube and the diameter outer tube, is heated up from $27^{\circ} \mathrm{C}$ to $180^{\circ} \mathrm{C}$. The total heat exchanged is equal to $12.7 \mathrm{~kW}$, the overall heat transfer 
coefficient is equal to $1324 \mathrm{~W} / \mathrm{m}^{2} / \mathrm{K}$ and the transfer area is equal to $9.5 \mathrm{dm}^{2}$. The selected inner tube diameter is $1 / 2$ " while the outer tube diameter is $3 / 4 "$. The length of both the inner and the outer tubes is $7.5 \mathrm{~m}$. Considering the operation flowrate $(223 \mathrm{~kg} / \mathrm{h})$, the residence time of the desuperheater outlet stream in the heat exchanger is equal to $13 \mathrm{~s}$. With this data and applying the fourth order Runge-Kutta method, it is possible to generate the glucose degradation evolution profile which is presented in Fig 8. In the generation of this profile it has been considered that the temperature decrease rate is constant.

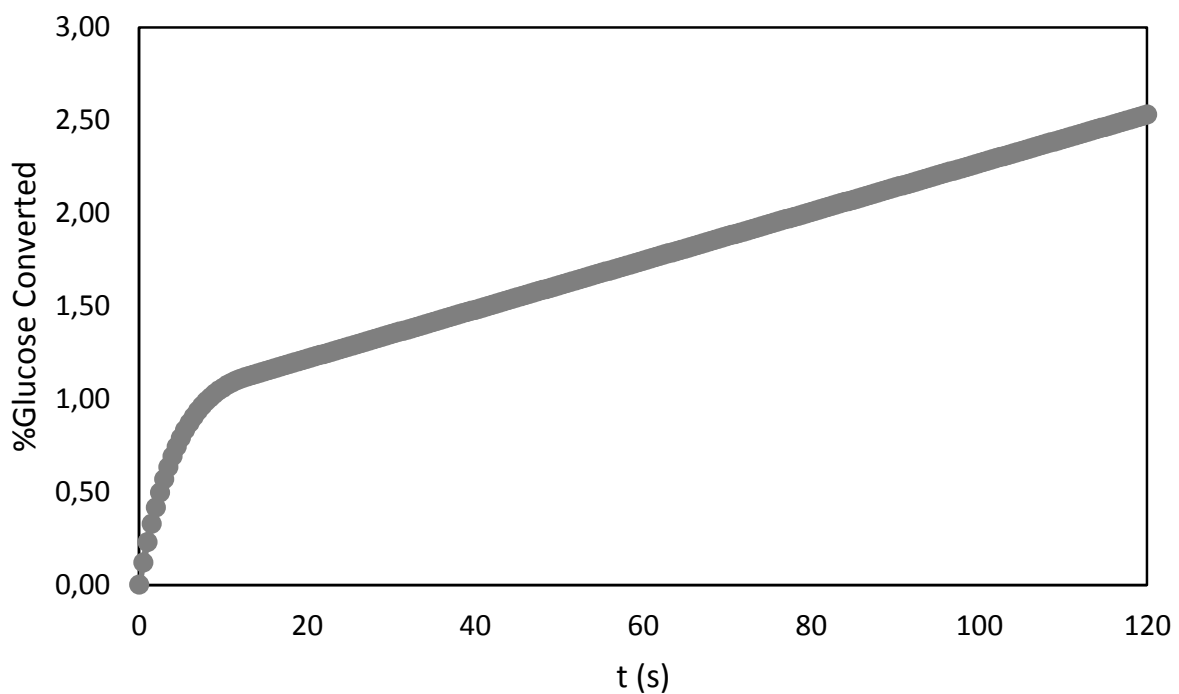

Fig 8. Glucose degradation evolution profile. Temperature decreases from $236^{\circ} \mathrm{C}$ to $190^{\circ} \mathrm{C}$ in $13 \mathrm{~s}$ and remains constant.

As it can be seen from Fig $\mathbf{8}$, the degradation rate is drastically reduced when the temperature has been decreased to $190^{\circ} \mathrm{C}$, which is produced in $13 \mathrm{~s}$ (heat exchanger residence time). This reduction in the degradation rate allows implementing a pressure recovery device without drastically penalize the selectivity which shall be as close as possible to the heat exchanger in order to reduce the residence time of the process. Immediately after the pressure recovery, the stream shall be cooled down to completely stop the reaction.

In order to show the glucose degradation profile in the whole downstream process proposed in this section, the final heat exchanger which cools down the product completely stopping the reaction has been designed. As in the previous case, the heat 
exchanger is a concentric tubes type one in which $223 \mathrm{~kg} / \mathrm{h}$ of water at $190^{\circ} \mathrm{C}$, is mixed with $3400 \mathrm{~kg} / \mathrm{h}$ of cooling water at $25^{\circ} \mathrm{C}$. The process stream (the desuperheater outlet stream) which flows along the inner tube is cooled down from $190^{\circ} \mathrm{C}$ to $45^{\circ} \mathrm{C}$ while the cooling water stream which flows along the concentric section created between the inner tube and the outer tube, is heated up from $25^{\circ} \mathrm{C}$ to $35^{\circ} \mathrm{C}$. The total heat exchanged is equal to $38.9 \mathrm{~kW}$, the overall heat transfer coefficient is equal to $976 \mathrm{~W} / \mathrm{m}^{2} / \mathrm{K}$ and the transfer area is equal to $60 \mathrm{dm}^{2}$. The selected inner tube diameter is $1 / 2$ " while the outer tube diameter is $2 "$. The length of both the inner and the outer tubes is $47 \mathrm{~m}$. Considering the operation flowrate $(223 \mathrm{~kg} / \mathrm{h})$, the residence time of the process stream in the heat exchanger is equal to $91 \mathrm{~s}$. Finally, taking into account that the residence time in the first heat exchanger is equal to $13 \mathrm{~s}$ and in the second heat exchanger is equal to $91 \mathrm{~s}$ and considering a residence time in the pressure recovery device of 10s, applying the fourth order Runge-Kutta method it is possible to generate the glucose degradation evolution profile of the whole process which is presented in Fig 9. In the generation of this profile it has been considered that the temperature decrease rate in both heat exchangers is constant.

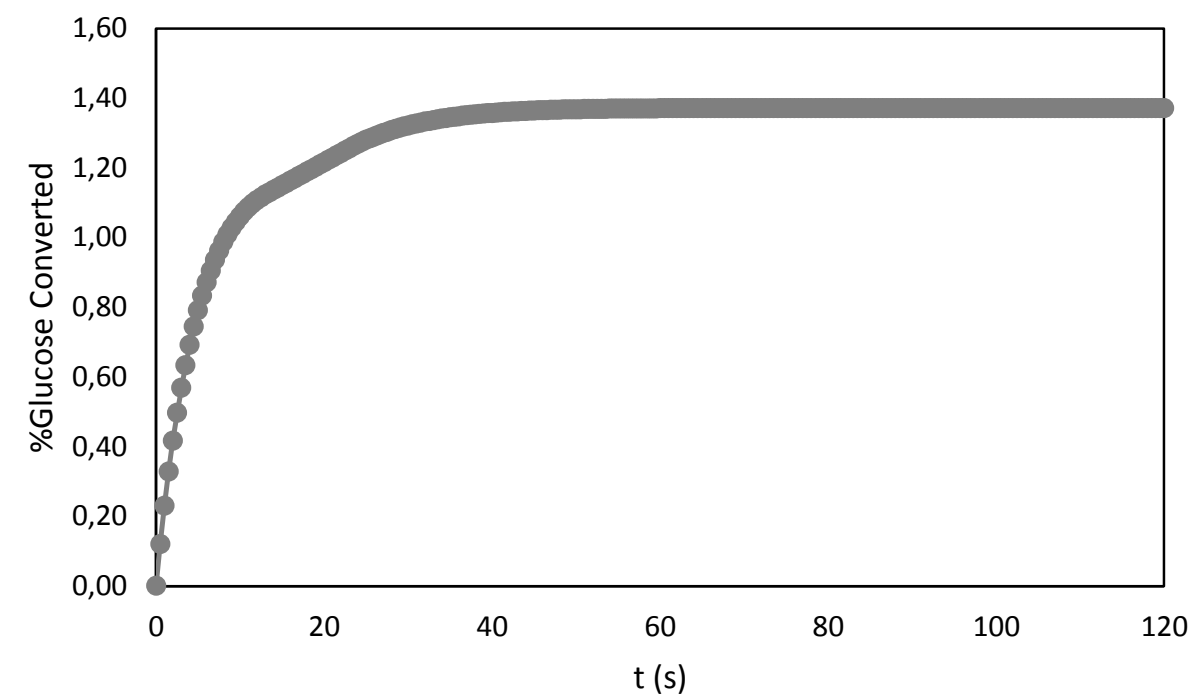

Fig 9. Glucose degradation evolution profile. Temperature decreases from $236^{\circ} \mathrm{C}$ to $190^{\circ} \mathrm{C}$ in $13 \mathrm{~s}$, remains $10 \mathrm{~s}$ constant and decreases to $45^{\circ} \mathrm{C}$ in $91 \mathrm{~s}$.

As it can be seen from Fig 9, the glucose degradation is stabilized at approximately $1.4 \%$ which can be considered an acceptable value since the pressure of the product 
stream can be recovered and the process water used in the hydrolysis reaction is preheated.

\section{Downstream process alternatives}

Once that the substitution of the expansion valve by a desuperheater has been validated, the different heat and pressure integrating possibilities of both downstream processes are presented and compared in Fig. 10 and Fig. 11. As it was previously stated, it has been considered that the influence of the hydrolysis products in the thermodynamic behavior is negligible. For this reason, the study is presented over the base of a pressure-enthalpy diagram of water.

Fig. 10 shows the downstream process alternatives of the supercritical water hydrolysis of biomass process implementing an expansion valve to stop the hydrolysis reaction. This process has been extensively studied by Cantero et al (Cantero et al., 2015, 2014, 2013a, 2013b, Danilo A. Cantero et al., 2015a, 2015b). Point 1 represents the outlet stream of the hydrolysis reactor. It is expanded in an isoenthalpic valve in order to cool down the products and stop the hydrolysis reaction. The maximum temperature in the outlet of the valve in order to retard the glucose degradation reactions shall be equal or lower than $250^{\circ} \mathrm{C}$, which corresponds with a pressure of 40 bara and a mass vapor fraction of 0.87 (Point 2). However, as it has been demonstrated in the previous section, it is necessary to cool down the hydrolysis stream below $200^{\circ} \mathrm{C}$ as fast as possible in order to avoid glucose degradation and consequently selectivity lost. The main advantage of this process alternative is the possibility of obtaining a concentrated product stream. If the product stream is expanded until atmospheric pressure, the $96 \%$ of the water remains in vapor state. It can be considered that the hydrolysis products and the solid which remain in the product stream are contained in the liquid phase. Thus, if the outlet stream of the valve is introduced in a flash vessel, it is possible to obtain a concentrated liquid final product stream with only the $4 \%$ of the water which is present in the hydrolysis stream. Regarding to temperature, since the vapor content of the valve outlet stream is elevated, it is possible to perform a heat integration in order to heat up the raw materials improving the energetic efficiency of the process. On the other hand, the intrinsic inefficient characteristic of this alternative is the waste of pressure in the expansion valve. Although the vapor content of the outlet stream of the expansion valve is elevated, it is not possible to implement a steam turbine since this steam is saturated. 
However, different alternatives as the STIG (Steam Injection Gas Turbine) process (Cantero et al., 2015), or the implementation of water turbines and pressure recovery devices in the liquid phase increase the global efficiency of the process.

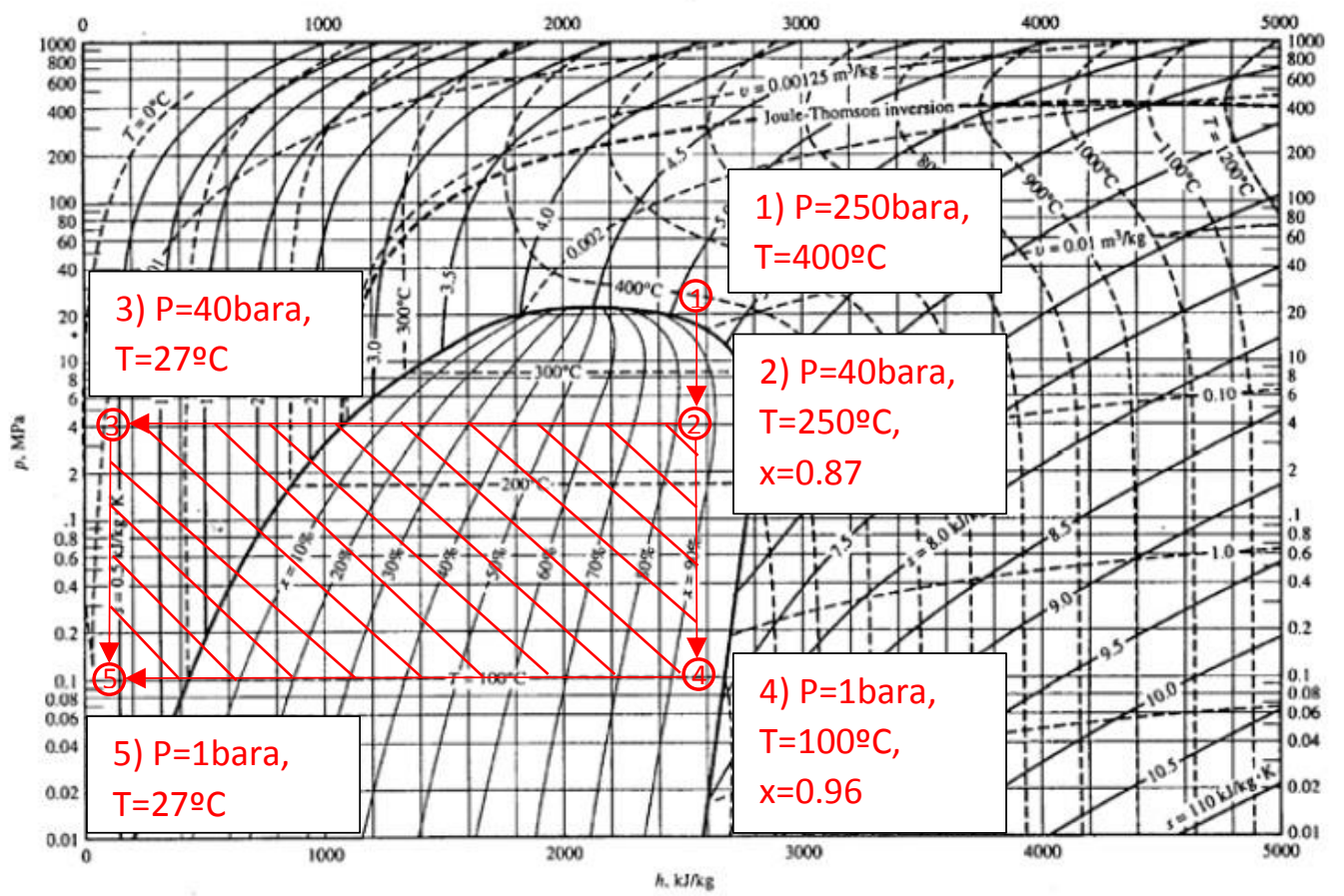

Fig. 10. Downstream process alternatives of the biomass hydrolysis with supercritical water using an expansion valve. Water pressure-enthalpy diagram.

Fig. 11 shows the different downstream process alternatives of the supercritical water hydrolysis of biomass implementing a desuperheater instead of an expansion valve to stop the hydrolysis reaction. Point 1 and Point 2 represent respectively the hydrolysis product and the pressurized cooling water stream. The mixture of both streams is represented in Point 3. A mixture temperature of $236^{\circ} \mathrm{C}$ avoids peaks of temperature inside the desuperheater above $250^{\circ} \mathrm{C}$. As in the traditional process, it is necessary to cool down the desuperheater outlet stream below $200^{\circ} \mathrm{C}$ as fast as possible to avoid selectivity lost. On the one hand, the main advantage of this process is the conservation of the pressure level after the hydrolysis reaction. Consequently, the implementation of either water turbines or pressure recovery devices increases the global efficiency of the process. On the other hand, the main disadvantage of this process alternative is the dilution of the product stream. As it can be seen from Point 4, a maximum of $27 \%$ of the total water present in the desuperheater can be evaporated by isoenthalpic expansion. Moreover, if the stream is used first in heat integration, the dilution of the final product would be even higher since the stream is being cooled down and therefore 
a lower amount or even none vapor can be generated by isoenthalpic expansion. Regarding to heat integration, the possibilities are similar to the previous alternative. As in the previous alternative, the implementation of a steam turbine is not considered since the steam obtained in the process is also saturated.

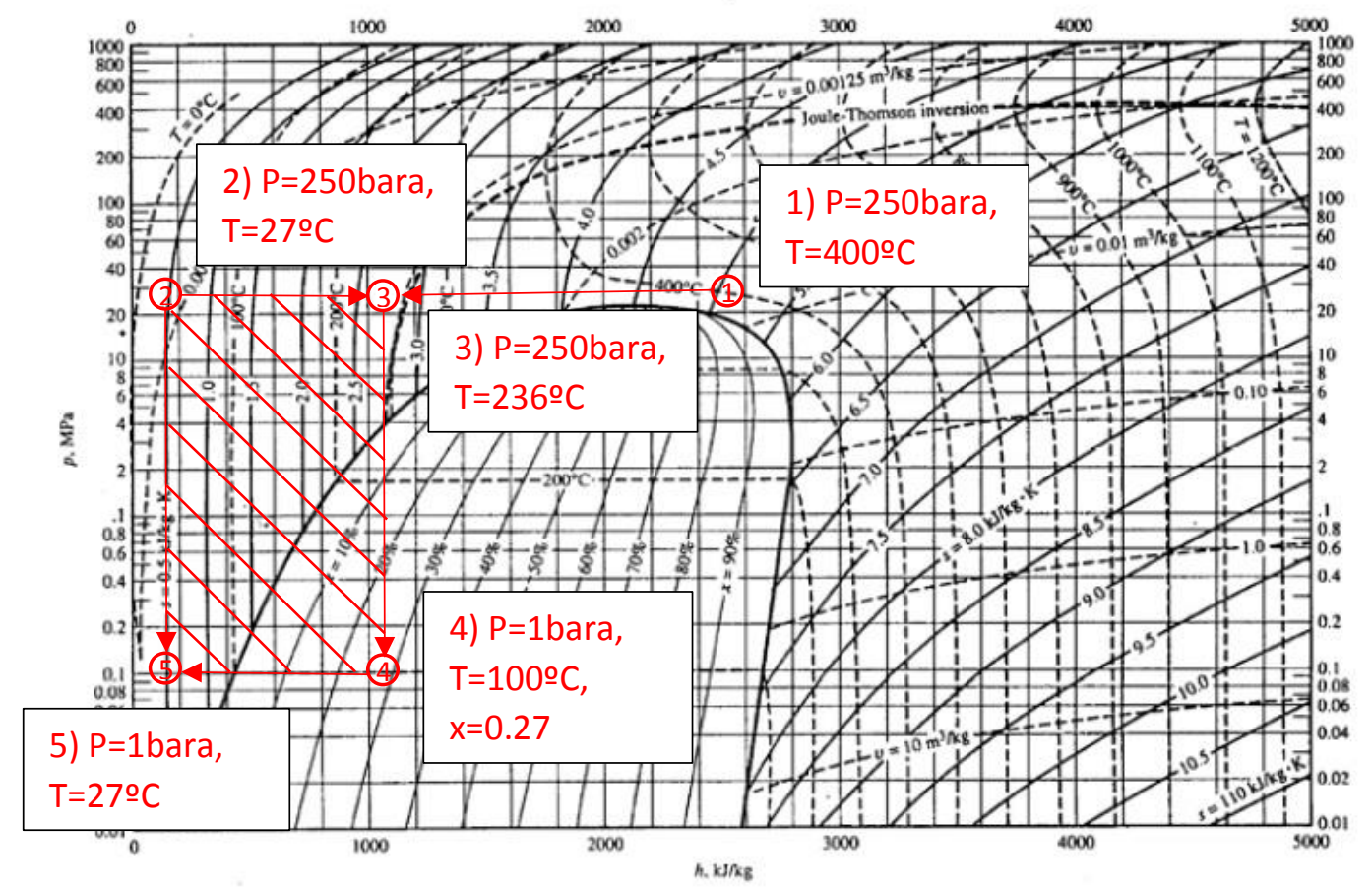

Fig. 11. Downstream process alternatives of the biomass hydrolysis with supercritical water using a desuperheater. Water pressure-enthalpy diagram.

Comparing both alternatives, it is stated that the use of an expansion valve to stop the hydrolysis reaction is recommended when a high concentration of sugars in the product stream is required. In this case, the implementation of a desuperheater is not favorable since the amount of heat which would be necessary to supply in order to be able to concentrate the final product stream would not compensate the increase of efficiency associated to the pressure recovery. On the other hand, when the obtaining of a concentrate product stream is not a requirement, the implementation of a desuperheater allows increasing the global efficiency of the process.

\section{Conclusions}

The supercritical water hydrolysis of biomass $\left(\mathrm{P}=250 \mathrm{bara}, \mathrm{T}=400^{\circ} \mathrm{C}\right)$ allows obtaining sugars directly from biomass. The use of supercritical water as reaction medium presents several advantages summarized in the intensification of the hydrolysis process 
due to the reduced hydrolysis times which vary in the order of milliseconds, the possibility of selecting the reaction pathways and consequently the final products obtained in the hydrolysis and the high selectivity values obtained in the process. The base of those advantages is the precise control of the residence time joined to the instantaneous cooling of the hydrolysis products which avoid the generation of byproducts. Both requirements can be simultaneously fulfilled implementing an expansion valve immediately after the hydrolysis reactor. The main disadvantage associated to any valve is the decrease in the pressure level which in this process considerably penalizes the global energetic efficiency. For this reason, the substitution of the expansion valve by a desuperheater which mixes the hydrolysis product stream with a pressurized cooling water stream has been analyzed. A CFD simulation of a desuperheater which mixes a hydrolysis product stream of $81.2 \mathrm{~kg} / \mathrm{h}$ with a cooling water stream of $141.8 \mathrm{~kg} / \mathrm{h}$ has been presented. The hydrolysis stream was considered as a water stream due to the low concentration of hydrolysis products $(1.27 \% \mathrm{wt})$. Moreover, due to the importance of a precise calculation of the physical properties, Ansys Fluent ${ }^{\circledR}$ was connected with Aspen Plus ${ }^{\circledR}$ which perform the calculation of the physical properties when required. The results obtained from the simulation prove that it is possible to reduce the temperature of the hydrolysis product stream from $\mathrm{T}=400^{\circ} \mathrm{C}$ to $\mathrm{T}=236^{\circ} \mathrm{C}$ (with peaks of temperature of $250^{\circ} \mathrm{C}$ inside the desuperheater) in a cooling time of $18 \mathrm{~ms}$ maintaining the pressure at $\mathrm{P}=249 \mathrm{bara}$. This almost instantaneous cooling process allows obtaining a minimum selectivity value of $93 \%$.

The kinetic study of glucose degradation has demonstrated that although a temperature of $250^{\circ} \mathrm{C}$ retards glucose conversion, it is necessary to cool down the product stream below $200^{\circ} \mathrm{C}$ in order to avoid selectivity lost. Although at this temperature, the glucose degradation proceeds, it is possible to implement pressure recovery devices without drastically penalize the selectivity. Nevertheless, downstream the pressure recovery device, the product stream shall be cooled down as fast as possible to ambient temperature in order to completely stop glucose degradation.

Analyzing the downstream process alternatives, it has been concluded that the main advantage of the implementation of a desuperheater is the increase of the global energetic efficiency associated to the maintenance of the pressure level and consequently the possibility of implementing water turbines or pressure recovery devices. On the other hand, the main disadvantage is the dilution of the hydrolysis stream when it is mixed with the cooling water stream obtaining a hydrolysis products 
final mass concentration of $1.2 \%$ when the temperature is decreased to $236^{\circ} \mathrm{C}$ in the desuperheater. This concentration value is approximately one third of the one obtained in the reactor outlet $(3.3 \%)$.

\section{Acknowledgements}

The authors thank MINECO and FEDER program for the financial support Projects CTQ2013-44143-R and CTQ2016-79777-R.

\section{References}

Adschiri, T., 2014.- Biomass Conversion in Supercritical Water, in: Supercritical Fluid Technology for Energy and Environmental Applications. pp. 89-98. doi:10.1016/B978-0-444-62696-7.00004-6

ANSYS, 2013. Ansys Fluent Theory Guide, Edition 15.

Arai, K., Smith, R.L., Aida, T.M., 2009. Decentralized chemical processes with supercritical fluid technology for sustainable society. J. Supercrit. Fluids 47, 628636. doi:10.1016/j.supflu.2008.11.008

Brunner, G., 2014. Processing of Biomass with Hydrothermal and Supercritical Water. Supercrit. Fluid Sci. Technol. 5, 395-509. doi:10.1016/B978-0-444-59413$6.00008-\mathrm{X}$

Brunner, G., 2009. Near critical and supercritical water. Part I. Hydrolytic and hydrothermal processes. J. Supercrit. Fluids. doi:10.1016/j.supflu.2008.09.002

Cantero, D.A., Bermejo, M.D, Cocero, M.J., 2015a. Reaction engineering for process intensification of supercritical water biomass refining. J. Supercrit. Fluids 96, 2135. doi:10.1016/j.supflu.2014.07.003

Cantero, D.A., Bermejo, M.D., Cocero, M.J., 2013a. Kinetic analysis of cellulose depolymerization reactions in near critical water. J. Supercrit. Fluids 75, 48-57. doi:10.1016/j.supflu.2012.12.013

Cantero, D.A., Dolores Bermejo, M., José Cocero, M., 2013b. High glucose selectivity in pressurized water hydrolysis of cellulose using ultra-fast reactors. Bioresour. Technol. 135, 697-703. doi:10.1016/j.biortech.2012.09.035

Cantero, D.A., Martinez, C., Bermejo, M.D., Cocero, M.J., 2015. Simultaneous and selective recovery of cellulose and hemicellulose fractions from wheat bran by 
supercritical water hydrolysis. Green Chem. 17, 610-618.

doi:10.1039/C4GC01359J

Cantero, D.A., Sánchez Tapia, Á., Bermejo, M.D., Cocero, M.J., 2015b. Pressure and temperature effect on cellulose hydrolysis in pressurized water. Chem. Eng. J. 276, 145-154. doi:10.1016/j.cej.2015.04.076

Cantero, D.A., Vaquerizo, L., Martinez, C., Bermejo, M.D., Cocero, M.J., 2014. Selective transformation of fructose and high fructose content biomass into lactic acid in supercritical water. Catal. Today 255. doi:10.1016/j.cattod.2014.11.013

Cantero, D.A., Vaquerizo, L., Mato, F., Bermejo, M.D., Cocero, M.J., 2015. Energetic approach of biomass hydrolysis in supercritical water. Bioresour. Technol. 179, 136-143. doi:10.1016/j.biortech.2014.12.006

Kouhikamali, R., Hesami, H., Ghavamian, A., 2012. Convective heat transfer in a mixture of cooling water and superheated steam. Int. J. Therm. Sci. 60, 205-211. doi:10.1016/j.ijthermalsci.2012.05.012

Piqueras, C.M., Cabeza, Á., Gallina, G., Cantero, D.A., García-Serna, J., Cocero, M.J., 2017. Online integrated fractionation-hydrolysis of lignocellulosic biomass using sub- and supercritical water. Chem. Eng. J. 308, 110-125. doi:10.1016/j.cej.2016.09.007

Prado, J.M., Lachos-Perez, D., Forster-Carneiro, T., Rostagno, M.A., 2016. Sub- A nd supercritical water hydrolysis of agricultural and food industry residues for the production of fermentable sugars: A review. Food Bioprod. Process. doi:10.1016/j.fbp.2015.11.004

Rahimi, E., Torfeh, S., Kouhikamali, R., 2016. Numerical study of counter-current desuperheaters in thermal desalination units. Desalination 397, 140-150. doi:10.1016/j.desal.2016.06.028

Sasaki, M., Fang, Z., Fukushima, Y., Adschiri, T., Arai, K., 2000. Dissolution and Hydrolysis of Cellulose in Subcritical and Supercritical Water. Ind. Eng. Chem. Res. 39, 2883-2890. doi:10.1021/ie990690j

Sinnot, R.., 2005. Chemical Engineering Design (Coulson \& Richardson's Volume 6), Fourth Edi. ed.

Vaquerizo, L., Cocero, M.J., n.d. New tool to improve computational fluid dynamic simulations by improving thermodynamic models description, Submitted Manuscript. AIChE J.

Zhang, K., Liu, Z., Li, Y., Li, Q., Zhang, J., Liu, H., 2013. The improved CO2 capture 
system with heat recovery based on absorption heat transformer and flash evaporator. Appl. Therm. Eng. 61, 500-506.

doi:10.1016/j.applthermaleng.2013.07.043

Zhang, K., Liu, Z., Wang, Y., Li, Y., Li, Q., Zhang, J., Liu, H., 2014. Flash evaporation and thermal vapor compression aided energy saving CO2 capture systems in coalfired power plant. Energy 66, 556-568. doi:10.1016/j.energy.2014.01.063 